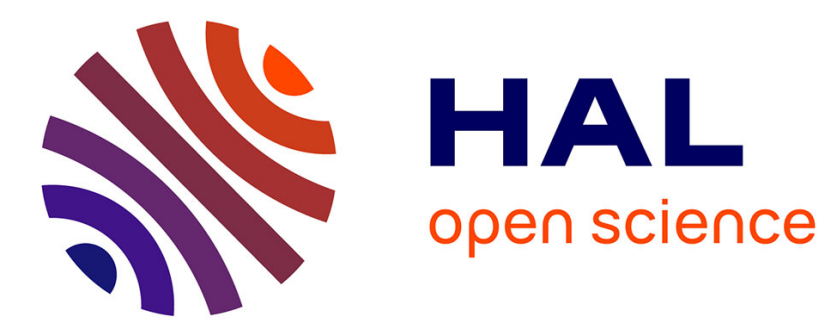

\title{
Mobile telecommunications and the management of time
}

Francis Jauréguiberry

\section{To cite this version:}

Francis Jauréguiberry. Mobile telecommunications and the management of time. Social Science Information, 2000, 39 (2), pp. 255-268. 10.1177/053901800039002005 . hal-01671101

\section{HAL Id: hal-01671101 https://hal.science/hal-01671101}

Submitted on 11 Jan 2018

HAL is a multi-disciplinary open access archive for the deposit and dissemination of scientific research documents, whether they are published or not. The documents may come from teaching and research institutions in France or abroad, or from public or private research centers.
L'archive ouverte pluridisciplinaire HAL, est destinée au dépôt et à la diffusion de documents scientifiques de niveau recherche, publiés ou non, émanant des établissements d'enseignement et de recherche français ou étrangers, des laboratoires publics ou privés. 
Publié dans la revue Social Science Information - Information en sciences sociales, vol. $39, \mathrm{n}^{\circ}$ 2, Londres-Paris, 2000, pp. 255-268.

Article disponible en ligne à l'adresse :

http://journals.sagepub.com/doi/abs/10.1177/053901800039002005

\section{MOBILE TELECOMMUNICATIONS AND THE MANAGEMENT OF TIME}

\section{Francis Jauréguiberry}

Man has always dreamt of being here and elsewhere at the same time, but this desire to be ubiquitous had up until now only ever been fulfilled for the community in myth and for the individual in his imagination - each of us has the capacity to cut ourselves off from the here and now and to mentally plunge into some other place and time. Mobile telephony has introduced what can only be called a staggering change in the way this fulfillment is experienced. Indeed, the mobile phone enables one to experience what is no longer just mental ubiquity, through the imagination, dreams or some intellectual fabrication, but also sensorial and verbal ubiquity, through the artificial extension of hearing and of speech. The two notions, here and there, originally following each other are being transformed into possibilities that have to be set in motion and managed at the same time. It is precisely with this notion of "simultaneity" that these few pages deal. ${ }^{1}$

\section{THE DENSIFICATION AND DIVISION OF TIME}

Like most of the other technological tools this century has given us, the mobile phone is largely a result of a utilitarian approach to progress which, as it concerns us here, consists of accomplishing more or doing better in the same time span. The mobile phone, for its first users, was indeed a tool that enabled them to reorganize their time so as to make it more profitable. The mobile phone allows one to make time denser thanks to better organization of the tasks at hand both as to their execution and processing order, in particular in "unstable" situations. By destroying communicational unity in space and in time, one no longer needs to be in a specific place to make a call at the same time. The mobile phone makes it possible for us not to be at a loss when confronted with last-minute hitches. Having to wait for an appointment will happen a lot less if one has a mobile phone; after a few moments, a hertzian exchange will let whoever is waiting know what is going on, thereby delivering him or her from any impression of waiting, the evil here being, according to the utilitarian approach, "lost time", the "suspension of time" and "vacant time". What is original about this reorganization of time to make it more profitable is the fact that it is achieved not only in the "traditional" way, through improved organization within a given timespan, but also in a new way, through the division of time thanks to the simultaneous superimposition of physical time and communicational time. The "double" physical time we are referring to here is usually either interstitial, or unoccupied or even ill-used, according to the logic of profitability. This is time necessarily spent traveling

\footnotetext{
${ }^{1}$ These largely pick up some of the findings of a series of research tasks carried out over a period of four years among the first mobile phone users in Paris, Strasbourg and Toulouse. The research was funded by the CNET and the CNRS, and carried out with the collaboration of François Menard, Liliane Sochaki and Sandy Torres in the SET (Société Environnement Territoire, unité mixte de recherche 5603 du CNRS).
} 
(physically) or sitting waiting- in a traffic jam, because of a delay or a change of plan; it is also time that has not turned out to have been used as planned either in how or in how intensively it has been used. The mobile phone allows one to extricate oneself from such temporal constraints that lead to "dead time" by giving us the opportunity to superimpose a second timespan for communication which will be more useful and therefore more profitable, without "murdering" (to use the same metaphor) the initial timespan. One can then go on moving in time with the flow of traffic at the wheel and at the same time exchange information on the mobile phone with one's secretary. Thus one is not just substituting one activity with another, or dealing with a task more quickly. One is superimposing them, dealing with them simultaneously.

\section{THE SPREADING OF URGENCY}

More and more time is spent responding to what is urgent. The habit is initially acquired in the working environment in which fast responses to market demands have become a key to the survival of firms. For these telecommunications are unavoidable: where production capacity is matched, only the firm that is readiest to provide data and is first off the mark to intervene will win the deal. The mobile phone has become as absolutely essential as the fax: they are both "real-time" tools used in the fight against the reality of time. In the economic war fought by the protagonists of stop-watch -competitively, these tools have been transformed into veritable weapons mobilized with the single aim of reducing given deadlines, accelerating the pace of work and expanding the application of such "simultaneity" as we have spoken of. Whether it be to win (or else what is much more likely) in order not to sink, one has to speed up operations. Economically speaking, time has become an investment the importance of which can be measured in this notion of urgency.

If urgency is something to be experienced as a negative disparity between on the one hand the time it should take according to one individual for a task to be carried out or for a project to be completed and on the other the actual time allotted in accordance with external constraints, both aiming at the same goal, then it can but be noted that urgency is no longer merely a feature of the working environment. It is invading the private sphere more and more every day. One of the main causes of this phenomenon is the occupational exploitation of telecommunicational ubiquity. Physical distance, walls and official working hours no longer provide any form of protection whatsoever. Day after day the notion of urgency is erupting into the private sphere by "colonizing" it; individuals are obliged to be on call or on duty or allow for telephonic digressions from home life.

Yet this spreading of urgency to the private environment is also the result of another factor which, although it is less perceptible, runs just as deep; that is, the way one functions at work influences the way one functions at home. In a diffuse way, the canons of contemporary economic rationality (pragmatism, utilitarianism, competition, profitability, efficiency, the desire for financial gain and power) are being applied to what is in the process of becoming the "management" of private activities and relationships. For example, if one adapts this utilitarian, time-is-money approach to leisure time, the following equation will exist: leisure time is precious because it has been hard earned; therefore one must be able as far as possible to get one's money's worth out of it. Flirting with the notion of urgency, then is also the fruit of a desire that is present, be it to varying degrees, in every mobile phone user: the desire to be 
everywhere at the same time, to save time, to multiply his or her opportunities in short, a veiled desire for power.

For the "wired", the crash scenario is not, as it would be in the working environment, financial disaster; rather it is a missed opportunity. Driven by the desire to make a success of every single second of their lives, carried along by the conviction that they have to be competitive and live every moment as intensely as possible, the wired are therein a perfect representation of today's individuals. At a time when religious salvation and social utopias no longer manage to define a life after death that is full of hope and gives people something to identify with and for which to mobilize their efforts, the individual has no other prospect to look forward to except that of his own life, a life that he must make a success of at all costs. ${ }^{1} \mathrm{He}$ is his own benefactor, the manager of his own resources, and so his reason for living can be measured up with the degree of intensity that life procures for him. Individual subjectivity seems then to have priority over any social determination. The Ideal Self each individual determines for him or herself always goes beyond the existing self in its intensity.

The rationale around a possible alternative and potentially better self does not automatically generate a form of urgency, but it does permit it by provoking last-minute changes of plan. Time is hurried along so as to seize an opportunity. This means being in a position not to miss anything, and that is one is listening (is wired) and on the ready to switch immediately (to zap) to what suddenly seems an improvement or more intensive. This opportunist attitude, which the user-friendly telecommunications systems seem to encourage, obviously stems from a "time-is-money" view, but it is as much motivated by an attempt to ease boredom and fill the void created by the reality of time compared with what today's individual ideally and narcissistically expects for himor herself. The mobile phone enables one to detach oneself from this feeling of disappointment by being plunged into telecommunicational realtime which though being just as much of a void as the reality of the time one is living though, is in one's eyes much more promising in the way of results. Compulsive behavior in the handling of mobile phones can as a result be observed. In a quest for an augmentation in the intensity of "real time" so as to escape the reality of time, the wired multiply their phone calls, keep listening in to their telephone voice mailboxes, worriedly check that the zone they are in is adequately covered and feverishly "tele-consult" their answering machines and so on.

As they are at the mercy of impulsive or last minute "zaps", the wired people's schedules become at once more elastic, more unpredictable and more disorganized. Impatience and uncertainly overwhelm them as they are caught in the illusion of results and possibilities. The resulting confusion can indeed disconcert them; they do, however, guarantee that "anything is possible". When one of these possibilities actually arises, the changes are all the hastier as they can be made known straightaway, wherever they might be, by means of a phone call. What must be stressed here is not the content of the urgent matter - in most cases it will make one smile - but the proclivity for the capriciousness that goes with it. This rationale around a permanent alternative accompanied by the tensions it creates, intensifies the environment in which everything becomes potentially precarious. Diaries are opened daily that refer to futures many of which are transformed because of one phone call at the last minute - before they have even existed, into past anterior.

\footnotetext{
${ }^{1}$ On this subject, see Alain Ehremberg (L'individu incertain, Paris, Calmann-Lévy, 1995).
} 


\section{UNCERTAINTY AND THE DISTORTION OF TIME}

If one accepts that the progression of time and the belief in the future are really two indicators of modernity (compared with cyclical time and the reproduction mode in traditional communities), and that the principal tools for the rationalization of this same time have been forecasts, plans and precision, one is entitled to wonder about the rationality in the development of certain ways of reacting to urgent matters and unknown, unforeseen factors. Indeed, one cannot be sure that moving away from the logic of precision-based planification so as to adopt a logic in which opportunity produces insecurity is actually an extension of the rationalization of one's existence. Too much planning and precision makes society more rigid, thus halting individual creativity; on the other hand, too much opportunism and too many unknown factors are likely to make individual actions unpredictable and create a society devoid of certainty. This process is easy to see in the practice of the above-mentioned temporal shortcircuiting which involves hurriedly modifying a timetable according to last-minute information. The nature of some of the short-circuits says much about the pervasion of urgency in this society of telecommunicational ubiquity. Just as the fax and e-mail allow one to catch up with time for example by overriding the final mail collection, the mobile phone can lead to a sort of distortion of time. Take an example of informing someone at the last minute that one will not be in time for an appointment because of a traffic jam. Being able to "repair the damage" of a delay before it has actually occurred brings about the relativization of time and imperceptibly produces an overall reduction of deadlines. One calculates one's movements down to the second, knowing that should something go wrong one can always resort to an urgent phone call to apologize. Fortunately this kind of call is not becoming the general rule, but the reduction of deadlines is.

The telephone makes it very easy for one to give the excuse of some last-minute hitch to cancel an appointment. Now judging by the admissions made by several of our informants, proffering the excuse of some non-existent urgent matter is a way of "adjusting a timetable" that is being used more and more. This can only mean that the concept of urgency (in general) has acquired such a highly important status for it to be proffered and, what is more important, accepted as a valid excuse. It has become very common practice to be so occupied by some urgent matter that one is obliged to cancel an appointment without any further formalities. Naturally the degree of liberty taken with the person at the other end of the line is commensurate with the degree of power one has over him or her. This fact only slightly alters the weight of our affirmations. Urgency always gets priority without necessitating any justification other than its own existence. The notion of urgency has become one of the possible strategies of the "zapper" who prefers what is sudden and better to what is certain but average.

The danger is that this kind of behavior is likely to render the very idea of "project" obsolete. A project requires a certain amount of confidence in the future. It is almost like betting on the future, expecting that the projected action will be possible. Of this one obviously cannot be sure; only one's confidence can allow one to put things off till later or to plan ahead or even to imagine for oneself what will be against what is. Yet if

\footnotetext{
${ }^{1}$ We do not deal here with the moral side of the issue. Let it just be noted that the celebration of "always having more" and "always doing better" seems, as an approach, to be changing into a set rule of behavior, the opportunism of which is encouraged to the expense of duty which is no longer justified by any grounds whatsoever.
} 
the present itself seems undefined and experienced as some kind of "ephemeral immediacy", how can one envisage a plan as something lasting 1 ?

\section{THE ZAPPER SYNDROME}

Trying to make up for lost time, the cult of the potential, the pervasiveness of urgency, the pressure put on people by immediacy and the multiplication of information provided - all these plugs the wired into a situation full of endless demands made on them to react and make ever more rapid decisions. This acceleration can be experienced as something positive - as contributing to the multiplication of activities and opportunities, as revealing certain as ye unexploited organizational potentialities, as a way of simplifying things or as reinstating the value of individual intuition in the management of business. It can also bring various types of satisfaction, in particular for some freelance professionals who, given that they experience this race against time as a series of new challenges, find it fascinating and rewarding. This acceleration can, however, make one feel dizzy and a fall cannot be ruled out.

The fact that the wired are in a permanent state of urgency means that they are indeed running the risk of only ever reacting on impulse in order to avoid what one might call the "traffic jam effect", namely the uncontrollable accumulation of information. When face with a series of urgent faxes and an endless series of phone calls, they have to act fast. The danger of such a reaction, apart from the obvious stress stemming from the resulting feverish activity - is to see thought and imagination replaced by a kind of "first things first" reflex. The wired then turn themselves into firemen trying to put out the emergency fire wherever it may occur. Phone calls have priority over people, faxes over letters and the pager brings everything forthwith to a standstill as if individuals or organizations were at the beck and call of whatever emergency might arise: what is to be ousts what is.

There are obviously situations in which necessity lays down the law. But the extension of this way of reacting is threatening to turn it into an actual way of working. The wired, by focusing on the immediate demands made upon them, are running the risk of suffering from what we have called the "zapper syndrome". The zapper syndrome is a combination of the symptoms of a latent sickness that lies in wait for those who are too unyielding in their experience of telecommunicational ubiquity, to the extent that they are completely absorbed by it. It is at the same time: worry over lost time, last minute situational stress, the unquenched thirst to be everywhere at the same time, the fear of missing something important, the dissatisfaction with hastily reached decisions, the obsessive fear of not being connected to the right network at the right time and the confusion brought about by having too much information in too short a space of time.

The zapper syndrome is "telecommunications sickness", a form of media nausea which affects the wired when they are swept into what one of our informers called the "vortex". As if under the influence of some centrifugal force because of the uncontrollable acceleration of events, the individual is completely divested of the meaning of his own actions. As he is obliged to meet the urgency of an ever-increasing

\footnotetext{
${ }^{1}$ Zaki Laïdi (Un monde privé de sens, Paris, Fayard, 1994) underlines the dangers that the absorption of the future by the present represents for democracy. When the political world believes that its legitimacy can be renewed by being aware of the immediate, it is losing its visionary power - the power that produces plans for the future; it is giving priority to its role as manager with the sole task of overcoming the constraints of the present. The reduction of the distance between managing the present and imagining the future is accompanied by a collapse of notions such as hope, expectation or political utopia.
} 
mass of information and to evermore frequent unforeseen factors he finds himself reduced to hanging on to whatever comes to hand so as not to sink, trying his luck and working out opportunist tactics. This protagonist is, then, driven not so much by strategical logic as by tactical logic enabling him to better adjust to a situation which he no longer masters.

\section{REDISCOVERING TIME}

The zapper's vortex is attractive - it is attractive, first of all, because the energy of the electric power that feeds it is that same energy to be found in the current economic system, that is based on the widespread practice of the management of "real time", and secondly, because it is difficult to escape the pressure it put on one. It is attractive, too, because the form that it gives to actions (the speed, the challenge, the zapping, the feeling of power) is not without a certain enjoyment. Finally, it is attractive perhaps because by accumulating time in a sort of continuous present, it distracts the individual (in the Pascalian sense of the word) - that is, it takes the individual's mind off the passing of time and in turn from potentially worrying existential issues. ${ }^{1}$

Yet this vortex also appears to be a danger one must avoid. When confronted with the overdiversification and frenzy it can engender, with excessive exposure to the unforeseeable - and the resulting stress -, with repeated fleeting situations experienced within a kind of eternal present, the individual will react. The origin of this reaction is the individual's critical reasoning that aims at not letting himself or herself be divested of his or her own temporality or one's own pace for the benefit of universal synchronization that would unite, "in real time", all those who are wired to the "global network" in some kind of totalizing compulsion. This critical rationale unravels what urgency has enmeshed. It reinstates the idea of duration and re-positions the individual in a context of continuity that enables him or her to get back into some kind of referential order. ${ }^{2}$ This critical rationale reintroduces time as something with depth - for the ripening of an idea, for thought and meditation when the clash of immediacy and urgency all too often force the individual to act on impulse.

This facet of time concerns the past, memories and the soul-searching which allow one to get back into some referential order. We are also referring to time for anticipation, apprehension or hope. Such moments are to be experienced during a pause, while one is waiting, as one postpones something or when keeping something at a distance. It can neither be superimposed nor divided up: the individual as a whole will be contained in it. ${ }^{3}$ It is a reminder that behind the deceptive appearance of what seems to be singular, universal and synchronous time (that of the hours on a watch, the days in a diary and the months on a calendar), time is heterogeneous. It reminds us that there is not just one allencompassing time but several kinds of time; it reminds one that in face of the mass entry of our society into a culture of immediacy, impulse and widespread urgency, there

\footnotetext{
${ }^{1}$ If in fact one accepts, with Heidegger that it is because of his "insertion in time" (Zeitigung) that the individual is aware of his "being in the world" (Dasein) and that this awareness is above all of his own finiteness (the being is aware of the time of his own death), then one may think that the compression of the present into immediacy is in fact a way of escaping from the anguish such an awareness brings about.

${ }^{2}$ For Georges Balandier (Le désordre, Paris, Fayard, 1988, p. 245), "the past also appears as a combination of points of reference with which can more easily take stock. There is, here, more than just a covering up of helplessness by means of the culture of nostalgia; rather, it is an attempt not to be caught up in some process the origin of which has been forgotten and the end of which is still hidden from view." ${ }^{3}$ For the origins of this individual temporality see Helga Nowotny (Le temps à soi. Genèse et structuration d'un sentiment du temps, éd. de la Maison des sciences de l'homme, 1992.).
} 
are moments that resist the acceleration process; there are lasting periods which cannot be hurried along, and instants that escape the logic of rapidity and financial gain. These moments, periods and instants are essential for the shaping of the self as an agent, that is as an actor capable of building his life independently. The present, then is not just the immediate, the instantaneous or "real time", but also a time for what has been passed on, a time for memory and soul-searching, or else a time for waiting, anticipating and hoping. This distanciation from the present moment enables the individual to find himself once again, but it enables him in particular to experience a certain kind of independence compared with the role of efficient manager that everyone (even a part of himself or herself) agrees to see him play.

\section{THE TEMPORAL EXPERIENCE OF THE WIRED}

The way the wired manage their time is the result of a rather "strained dialogue" between two logics of action, bearing in mind that the one cannot quite cover the other. On the one hand, we have a logic of rapidity and financial gain that involves connection, synchronization and urgency; on the other, the logic of criticism that involves keeping some time for oneself, establishing temporal breathing space for oneself that is unique, incomparable and unquantifiable.

When the wired live in a way that is too strongly dependent upon the logic of rapidity, financial gain and synchronization, their world will collapse all round them and they will be swept into the vortex of the zapper. The determination (when it does exist) to escape from it often gives birth to the relentless pursuit of their goals. On seeing that they are being possessed by uncontrolled acceleration, the wired, "overtaken by events", foster the hope that even more profitable management of their time will spare them from being pulled down into the zapper's vortex. Their communicational exasperation then often has the effect of increasing their desire for technology. On the lookout for new discoveries, they think that a network with a wider range, more intelligent transmission or new multifunctional terminals will give them back a little time and will enable them to find themselves again. By consciously or unconsciously submitting their lives to the logic whereby time has to be made profitable, the advocates of this attitude often have no choice other than the relentless pursuit of their aims. Whether they be craftsmen, freelance workers, or else "fall-guy executives" in a given hierarchical organization, they almost never have the means to afford secretaries who could lighten the load in this influx. Even if they could afford secretaries (and here lies one of the most perverse aspects of such behavior), some of them would refuse them. As they are so used to dealing straightaway with calls that come in, they could not bear delegating decisional power, or the delays the employing of secretarial staff would mean to them.

When, on the contrary, the life of the wired is totally dominated by the logic of distanciation, authentic experience becomes necessary as does subjectivistic withdrawal in which the only aim is keeping some time for themselves. There is a great temptation to make a distinction between calls. On the one hand, there would be profitable calls with financial promise and strategic importance for which prompt dealing will contribute to success, and on the other, disinterested, intersubjective, convivial calls for which one does not have one's eye on the clock. On the one hand, we have the useful call and the other what is "real communication". Nomadic telecommunications can be associated with the first type in their very capacity to organize the second, which is face to face. However, this attitude sometimes goes to the extreme that involves wanting to avoid the evil by getting rid of what seems to be the cause: the very tools of 
communication themselves. Judging by the statistics (which show a general tendency to want to be equipped with telecommunicational tools), this behavior pattern is, in its full form, merely the exception and not the rule. Mostly it only applies to the private sphere and is a violent reaction to the fear of seeing relationships with family and friends perverted by the same logic of rapidity and financial gain that is part of the working sphere. The resulting solution is a short, sharp one: the complete disconnection of the home.

This relentless pursuit and this refusal are two types of behavior that represent a break with the experience of being wired. Both stem from the incapacity to combine the desire or the necessity to be wired with the wish to keep some time for oneself. On the contrary, living the wired experience to the full is a result of the heterogeneous nature of the logic of action that determines it: on the one hand there is the utilitarian aspect, guided by the concern for competency, efficiency and financial gain on the other, the critical approach that is motivated by the determination not to submit the whole of one's life to the constant synchronization of one's activities.

The result is behavior involving compromise, cunning and the use of fine tactical judgment that enable one to combine these two demands as best one can. This behavior essentially involves setting up intelligent filters in between the network (synchronization) and the agent (with the reflex to stand back, to keep some time for oneself). It's a question of maintaining contact without becoming a slave to the system. These filters usually take the form either of a third party (in particular, secretarial staff in the workplace and wives or children in the home), or a mechanical system for delaying answers (a voice mailbox on the mobile phone, a pager, an answering machine and the fax) or a filtering system in real time (answering machine).

Obviously keeping a balance is not easy and adjustments must be regularly made. Situations do exist in which the zapper's vortex is more attractive than in others, in which one's critical determination to stand back and to individual reserve one's individual temporality wins the day. It is however precisely because there is no final solution to the problem that one can refer to the person who gives himself up to this never-ending job of making experience coherent as an independent agent who is the active subject of his own life.

\section{CONCLUSION: A NEW TYPE OF INEQUALITY}

The image of the wired as being people who are in a hurry playing with space so as to be on intimate terms with time is not a false one. In fact it is very close to one of the realities in the life of the wired. Yet it is only a cliché - always the same one - in which enthusiasm seems to be sufficient to justify the race. The experience of the wired is much more complex. Far from being reduced to one single type of utilitarian behavior, the use of the mobile phone also makes one consider other types of behavior, especially those that aim at keeping some time for oneself. The filter techniques and the new possibility for putting off replies they allow for, can only be understood within the critical logic we have mentioned. They are essential as they make it possible again for individuals to manage their own temporal environments. Yet this control is decidedly inegalitarian. Situations exist (professional and existential ones) in which it is impossible for some people to filter calls, which then have to be answered straightaway; in other situations people have the power to switch off their phones whereas others are duty bound to leave them on. 
The obligation to have one's phone switched on and therefore to suffer from the tension brought on by the prospect of some emergency leads us to suggest that a new category of "nouveau riche" and "nouveau pauvre" is appearing among those who are wired. The nouveaux riches of the telecommunications age will be those who will have the means to filter solicitations and distance themselves from them. If such a hypothesis were proven true, it would then be highly likely that a new awareness of this issue would arise and that a new social, organizational controversy might arise, in particular over the following rights: the right to switch off and isolate oneself, the right to refuse to wear a pager twenty-four hours a day or be reachable by radiotelephone anywhere and everywhere, the right to the dignity of the individual who cannot be reduced to a mere function or a controllable resource or turned into a "tele-slave" with as an excuse some urgent matter, and finally the right to have some time to oneself, a right which would not be conceived of as a sanction, as some kind of escape or as a withdrawal into oneself.

The logic of action for the "wired" is dominated by cost effectiveness and utilitarianism. They want to live faster, better, more intensely, not only by increasing the density of time (better organization of the execution and order of tasks thanks to flexible telecommunications) but by creating a double time (superimposing media time on physical time). Nevertheless, in the face of random, fleeting experiences leading to the dispersion and sometimes aberrations that can be the outcome of such a logic, we see a reaction emerging which is based on a critical logic aimed at enabling individuals to avoid being dispossessed of time of their own, of their own rhythms and history by generalized acceleration. This logic reintroduces the temporal depth needed for maturation, for reflection and for meditation where the clash of immediacy and urgency all too often demands an impulsive response.

Sociology of uses, telecommunications, time management, ubiquity, urgency 